\title{
Thiopentone sedation for sedation of acutely agitated, violent, intoxicated patients: Evaluation of 2 cases
}

\author{
Marten C. Howes • Werner Janse van Rensburg
}

Received: 4 November 2008 / Accepted: 4 January 2009 / Published online: 24 February 2009

(C) Springer-Verlag London Ltd 2009

\begin{abstract}
Two cases of violent, drug-intoxicated patients who presented considerable problems in management, and were resistant to standard sedative agents, are described. Effective and safe sedation, without the need for full anaesthesia and endotracheal intubation, was achieved using titrated doses of thiopentone. The merits of selecting this agent in these circumstances are discussed.
\end{abstract}

Keywords Emergency $\cdot$ Sedation $\cdot$ Thiopentone

\section{Patient 1}

An adult male was brought to our department by ambulance with police in attendance. He had been destroying furniture, shouting and swearing. The patient was well known to the local psychiatric services and our emergency department (ED). A history of frequent attendances with mania, and violent and manipulative behaviour, was well documented. He was given the following sedation over the next $20 \mathrm{~min}$ : Haloperidol $15 \mathrm{mg}$ IV, Midazolam $15 \mathrm{mg}$ IV and Chlorpromazine $100 \mathrm{mg}$ po. He continued to be verbally abusive and difficult to contain in the open environment of our department. Over the next 2-3 h he received Midazolam $20 \mathrm{mg}$ IV, Clonazepam $2 \mathrm{mg}$ PO and Haloperidol $15 \mathrm{mg}$ IV. The patient remained restless, agitated and prone to violent verbal outbursts.

The patient was assessed by a consultant psychiatrist at 0800 hours. A collateral history of deteriorating mental

M. C. Howes $(\bowtie) \cdot$ W. J. van Rensburg

Emergency Department, Bunbury Regional Hospital,

School of Primary, Aboriginal and Rural Health Care/Rural

Clinical School of Western Australia,

P.O. Box 5301, Bunbury 6231, Western Australia

e-mail: Marten.Howes@health.wa.gov.au state over the preceding few weeks with insomnia, elevated mood, irritability and increasing alcohol and tetrahydrocannabinol (THC) use was obtained from the patient's mother. Pressure of speech, elevated mood and irritability were noted. Significant tolerance to benzodiazepines was noted from previous attendances. He was referred to the nearest secure psychiatric facility (in Perth). Haloperidol $20 \mathrm{mg}$ and Clonazepam $2 \mathrm{mg}$ were then given orally. Discussion with the duty ED consultant (the author) then occurred regarding transport and sedation options.

It was decided that deep sedation or general anaesthesia were the only safe options to allow the safe air transport, thus necessitating skilled medical escort. The only suitable agency qualified and able to perform the inter-hospital transfer in Western Australia is the Royal Flying Doctor Service. Although the distance to Perth is relatively small $(190 \mathrm{~km})$, no road transport with skilled medical escort is available.

A rapid sequence induction of anaesthesia was deemed too hazardous to contemplate before attempting the less invasive option of deep sedation. Thiopentone was selected as the most suitable sedative. The patient had no known exposure to barbiturates, and the ED consultant was familiar with its use.

The patient was moved to a fully equipped resuscitation bay. Secure IV access was confirmed, and a 1-1 bag of $0.9 \%$ saline was running in freely. Supplemental oxygen was delivered. An experienced nurse and a resident medical officer were present, in addition to two security personnel. Thiopentone was administered in $25-\mathrm{mg}$ increments to a total of $125 \mathrm{mg}$, where the patient attained a state of unconsciousness but was still breathing spontaneously and supporting his own airway. He was then put into a left lateral "recovery" position. A further two doses of $25 \mathrm{mg}$ IV Thiopentone were given over the next $2 \mathrm{~h}$, during which 
the patient was observed to be "sleeping" and "cooperative". There was no observed oxygen desaturation, hypotension or airway loss. The patient was escorted to the local airstrip, a 7-min road trip by ambulance, by an experienced paramedic crew. No intervention was required and on arrival the patient was given a further $50 \mathrm{mg}$ IV Thiopentone and loaded into the aircraft. The short flight to Perth was uneventful.

\section{Patient 2}

An ambulance was called to an agitated adult male with a past history of IV substance abuse walking along a rural road. He had taken a "hand full" of Diazepam tablets and an unknown quantity of Promethazine tablets with the hope that he would lose consciousness and be struck by a car. The uncooperative male was transferred by road with police officer escort. He became increasingly aggressive and was given Diazepam (total of $10 \mathrm{mg}$ ) and Midazolam (total of $5 \mathrm{mg}$ ) with little effect. The police officer proceeded to apply handcuffs.

On arrival at Bunbury ED he was promptly assessed by the ED consultant (WJvR) who noted a patent airway, tachypnoea with clear equal air entry and normal oxygen saturation, good peripheral perfusion, temperature $37.4^{\circ} \mathrm{C}$, blood sugar level $5.4 \mathrm{mmol} / \mathrm{l}$ and ECG unremarkable apart from the sinus tachycardia. The patient was agitated and uncooperative, struggling against the physical restraints and not responding verbally in any coherent manner. A further unsuccessful effort was made to achieve chemical restraint using titrated IV Midazolam (24 mg total in ED), Diazepam (5 $\mathrm{mg}$ total in ED) and Haloperidol (15 mg total in ED).

The ED consultant then proceeded with titrated doses of IV Thiopentone; $100 \mathrm{mg}$ was administered slowly followed by a further $100 \mathrm{mg}$ dose. The patient became progressively more sedated allowing the medical and nursing staff to provide monitored care focussed on supportive measures. At no stage after the administration of Thiopentone was there any compromise of the patient's vital functions. Once the situation was controlled staff could provide safe ongoing care whilst feeling less threatened. The overall improvement in the function of the ED was also noted. The patient remained calm and was reviewed $8 \mathrm{~h}$ later by the duty psychiatrist.

\section{Discussion}

EDs are increasingly faced with the problem of agitated, intoxicated and confused patients $[1,2]$. Many abuse a combination of substances and have tolerance to the standard sedatives available to ED practitioners, and with which they are familiar. Frequent dosing, with little or no short-lived effects, results in ongoing risks to staff and patient. Many modern substance abusers are naive to barbiturates, but may be highly tolerant of benzodiazepines [3]. When emergency physicians are selecting a sedative agent for an acutely agitated and violent patient they need to consider various factors including safety [4].

Thiopentone was selected in these two cases as the most suitable sedative. The patients had no known exposure to barbiturates, the drug was readily available, and its use and side effect profile were well known to the ED consultant.

Barbiturates were frequently used historically as sedatives, induction agents, and for conscious sedation, then became less popular with the advent of agents with shorter duration of action and less lethality in overdose $[5,6]$. As a result, doctors and patients are less familiar with them. This leaves a population naive to barbiturates and gives a more predictable clinical effect for clinicians. Thiopentone is familiar to emergency physicians as an agent for the rapid sequence induction of anaesthesia in emergency situations. Catastrophic cardiovascular decompensation, and airway loss, can occur in emergency situations and practitioners need to be aware of potential complications, and how to deal with them effectively. Caution should be exercised by those practitioners unfamiliar with the drug, and standard recommendations regarding sedation practice should be followed, in particular the immediate availability of advanced resuscitation skills.

\section{Conclusion}

These cases highlight the stepwise increase in sedative interventions, to allow safe ED management and a safe inter-hospital transfer. It was clear that conventional sedative options had been unsuccessful. Barbiturate naivety amongst the modern substance-abusing population may aid emergency physicians to select thiopentone as a suitable sedative agent in this situation. Safe sedative practices must be observed, including skilled medical availability in a suitable resuscitation environment. Further evaluation of drugs used for indications other than the sedation of agitated ED patients is warranted, as suggested by Knott and Isbister in a recent editorial [7].

Author's contributions $\quad \mathrm{MH}$ treated patient 1, WJvR patient 2. Both authors performed a literature search. MH wrote the paper, WJvR contributed to drafts.

Conflict of interest The authors declare that they have no conflict of interest ordisclosures.

Funding No funding was received. 


\section{References}

1. Gray SD, Fatovich DM, McCoubrie DL, Daly FF (2007) Amphetamine-related presentations to an inner-city tertiary emergency department: a prospective evaluation. Med J Aust 186(7):336339

2. Degenhardt L, Roxborough A, McKetin R (2007) Hospital separations for cannabis- and methamphetamine-related psychotic episodes in Australia. Med J Aust 186(7):342-345

3. Spain D, Crilly J, Whyte I et al (2008) Safety and effectiveness of high-dose midazolam for severe behavioural disturbance in and emergency department with suspected psychostimulant-affected patients. Emerg Med Australas 20:112-120

4. Australasian College for Emergency Medicine (2003) Statement on Clinical Principles for Procedural Sedation. ACEM Policy Document P29, ACEM

5. Dubin WR, Weiss KJ, Dorn JM (1986) Pharmacotherapy of psychiatric emergencies. J Clin Psychopharmacol 6(4):210-222

6. Austin T, Vilke GM, Nyheim E et al (2003) Safety and effectiveness of methohexital for procedural sedation in the emergency department. J Emerg Med 24(3):315-318

7. Knott JC, Isbister GK (2008) Sedation of agitated patients in the emergency department. Emerg Med Australas 20:97-100 